Misplaced complacency about energy resources

Sir - In his letter "Flawed reasoning about oil and gas", Maurice B. Dusseault (Nature $386,12 ; 1997)$ criticizes the review by Peter Kassler of a book by Marcello Colitti and Claudio Simeoni entitled Perspectives of Oil and Gas: The Road to Independence (Nature $384,528 ; 1996)$. Both the review and the letter are really having a go at writers who face the finiteness of fossil fuels and seek to stir up some discussion about how the human race will organize the economics under the threat of scarcity.

Industries and big centres of population are built around indigenous resources, and they have ultimately to look elsewhere, usually in unindustrialized countries, for resources so that they can continue their enterprise. A pattern of life is thus developed that depends very fundamentally on a continuing supply of energy.

Neither writer recognizes that global pollution has become a pressing problem. Kassler is not bothered by the difficulty of the continued supply of fuel, although he has a slight worry because oil supply has become a "political football". He relies on a vigorous free market "to keep my children's feet warm in their old age".

Dusseault pretends, typically of an economist, that there is no problem because the Canadian heavy oil deposits are "sufficient to meet current US and Canadian consumption combined for more than a hundred years". Canadian "political and military disruptions are modest, compared to recent Middle East events". The struggle for political power over oil supplies and the problems of climate change and local pollution, due to using the residual difficult mineral fuels, are all seen as technologically soluble now and within the foreseeable future.

Environmentalists and others, who see humanity's future as being at least as extensive as our recorded historical past, do not see the advances achieved in the past two-and-a-half centuries being simply put into reverse. Even if the world population is stabilized as soon as 2050 at 10 billion, it will not be living in the right places for the development of the shales. And even if we have all learned to live on orimulsion and try to cultivate the world like a garden, it will lack its forests and we shall be the enemies of all other species - except possibly for the flocks of clones we enslave to serve our crude purposes (in a vigorous free market — or will it be a battlefield?).

\section{R.S. Scorer}

Department of Mathematics,

Imperial College,

London SW7 2BZ, UK
Sir — In recent months, Nature has brought us two highly imaginative alternatives to conventional fossil fuel. The first, where petrol is produced by "adding leaves and bark extracts from a native herb to tap water," has tragically turned out to be a hoax (Nature 383, 112 \& 384, 106; 1996). Let's hope that Dusseault's suggestion fares better.

Pointing out that "as conventional oil deposits are gradually depleted, prices will rise," thereby making "non-conventional resources economically accessible", Dusseault states that "one may even extract carbon (from atmospheric carbon dioxide or limestone) and hydrogen (from solarpowered electrolysis of water) and assemble synthetic gasolines from the basic elements". He adds: "The only realistic limitation to this process is price."

While I salute Dusseault for his bold attempt to liberate us from the constraining fetters of thermodynamics, I think he has overlooked an even simpler solution to the problem. All cars come equipped with a battery and an electric starter-motor. So why not dispense with petrol altogether and let the starter-motors do the work?

\section{Douglas Axe}

Department of Chemistry,

University of Cambridge,

Cambridge CB2 1EW, UK

\section{Habitable moons}

Sir - The recent discussion of habitable moons by Williams et al. and by C. Chyba (Nature 385, 234-235 \& 201; 1997) is prefigured in some science fiction, with implications for the extent of the habitable zones around stars.

In 1975, Poul Anderson wrote a description of such a habitable moon to form the background for a set of stories written as part of a science fiction seminar at the University of California, Los Angeles. (The essay and the stories are collected in Medea: Harlan's World, ed. H. Ellison, Bantam, 1985.) In this he pointed out that, as large gas giants are reasonably hot bodies themselves, they could warm the moons orbiting them. Thus a moon orbiting a superjovian planet outside the normally accepted habitable zone might be able to support liquid water, thanks to the added heat flux from its primary. The habitable zone for moons could thus be larger than that for solo planets.

In a separate essay undertaken for a similar exercise in collaborative world building (Murasaki, ed. R. Silverberg, Bantam, 1992), Anderson points out that the habitable zones around small red dwarfs will be very close to the star and that small planets within this zone may well be tidally locked. Having one permanently heated side and one cold side may render the 'habitability' of such planets somewhat theoretical. Anderson's solution to this problem was a pair of rocky planets in orbit around each other. An alternative scenario for true habitability in such a close orbit would be a rocky moon. It could be tidally locked to its own primary, rather than to the star, and thus could have a less problematic day/night cycle, perhaps of the order of ten days rather than 100. It would also benefit some of the time from nightside warming by its primary.

\section{Oliver Morton}

3 Hoskins Street,

London SE10 9NZ, UK

e-mail:omorton@wired.co.uk

\section{Malicious referees}

Sir - Simon Wain-Hobson is by no means the first to express dissatisfaction with the refereeing of papers, and won't be the last (Nature 385, 384; 1997). I second his proposal for reviews to be of a sufficient length - say 10 per cent of the paper's length for a rejection, 5 per cent otherwise?

There is another change that would not only improve the quality of reviews and consequent decisions but also make the editorial decision-making process more efficient. The idea is that editors should not examine referees' reports initially but should send them immediately to authors, and then if, and only if, the author feels he or she has a credible defence against the reviews will she or he then submit his or her response to the editor for consideration. Reviewers would then know that they could not get away with sloppy or malicious reviews. And editors would be saved the work of trying to weed out poor papers that can slip through the less controlled review process that is the current norm. This could go some way towards reducing the massive volume of poor-quality papers being published.

Meanwhile, authors could copy the trick I once used of compiling a collection of previous reviews of the paper along with my rebuttals, and sending that with the submitted manuscript to the next journal. It worked for me. The paper involved was described by a reviewer for Personality and Individual Differences as well-written, wellargued and well-documented, whereas a British Journal of Psychiatry reviewer reckoned it was of lowest grade in all three respects!

It is difficult to see how this gross discrepancy can be accounted for except in terms of malice on the part of the latter reviewer, such as I encountered with many previous reviews.

\section{R. P. Clarke}

Abnormal Psychology Research Institute,

9 Augusta Road East,

Moseley, Birmingham B13 8AJ, UK

e-mail:rclarke@fineart.demon.co.uk 